\title{
REFLEXÃO SOBRE ETNOMATEMÁTICA COMO POSSIBILIDADE PEDAGÓGICA
}

\section{ARTIGO ORIGINAL}

SCHWANTES, Vilson ${ }^{1}$

XAVIER, Márcio Pizzete ${ }^{2}$

SCHWANTES, Eloísa Bernardete Finkler ${ }^{3}$

SCHWANTES, Daniel ${ }^{4}$

${ }^{1}$ Mestre em Educação nas Ciências - Matemática, pela UNIJUI - RS. Graduação e Especialização em Ciências e Matemática. Prof. Assistente do CCA - Centro de Ciências Agrárias, Campus de Marechal Cândido Rondon, UNIOESTE, PR - Brasil.

2 Mestrando em Desenvolvimento Rural Sustentável-UNIOESTE, Especialista Em Matemática, Física-UNIPAR, Gestão De Pessoas E Educação Especial com Ênfase Na Deficiência Múltipla-UNIASSELVI, Graduado Em Matemática Com Ênfase Em Física-UNIPAR.

${ }^{3}$ Especialização em Ensino de Ciências Exatas - Matemática, Física e Química. UNIOESTE - Universidade Estadual do Oeste do Paraná. Graduação:Ciências e Matemática. UNIJUI, RS. Professora da Rede Estadual de Ensino do Estado do Paraná.

4 Professor da área de Proteção de Plantas e Saúde Humana da Pontifícia Universidad Católica de Chile, Departamento de Ciências Vegetales, ocupa um cargo interdisciplinar compartilhado entre a Facultad de Agronomía e Ingeniería Forestal (FAIF), Facultad de Medicina y Facultad de Química. Professor pesquisador associado ao Grupo de Estudos em Solos e Meio Ambiente (GESOMA - UNIOESTE). Mestre em Agronomia pela UNIOESTE, Doutor em Agronomia pela UNIOESTE (2013-2016) - Período Sanduíche (Bolsista CAPES) pela Universidade de Lisboa, no Instituto Superior de Agronomia (ULisboa). 
JUNIOR, Affonso Celso Gonçalves ${ }^{5}$

KRACKE, Elisa ${ }^{6}$

JUNIOR, Élio Conradi ${ }^{7}$

SCHWANTES, Vilson. Et al. Reflexão sobre etnomatemática como possibilidade pedagógica. Revista Científica Multidisciplinar Núcleo do Conhecimento. Ano 04, Ed. 07, Vol. 11, pp. 148-165. Julho de 2019. ISSN: 2448-0959

\section{RESUMO}

Este artigo reflete sobre a etnomatemática como uma tendência do ensino que considera a natureza cultural da aprendizagem matemática, o contexto social onde este saber se desenvolve, o papel do professor no contexto mais amplo das relações humanas ao assumir-se investigador e mediador consciente da prática pedagógica. A pesquisa considera a importância da história do saber matemático, suas múltiplas relações com outras áreas do conhecimento e sua inter-relação com as atividades

${ }^{5}$ Bolsista Produtividade em Pesquisa nível $1 \mathrm{C}$ pelo CNPq na área de Ciências Ambientais com três Pós-doutorados, UEM-PR (Brasil), Universidade de Santiago de Compostela (Espanha), UFG-GO (Brasil). Atualmente é Professor Associado da UNIOESTE-PR e atua como docente e pesquisador do Centro de Ciências Agrárias, ministrando aulas na área de Química. Docente no Programa de Mestrado em Ciências Agrárias da UEM. Atualmente é consultor ad hoc do CNPq, CAPES e Fundação Araucária. Atua como consultor ambiental voluntário junto ao MP-SP e CONAMA-DF.

${ }^{6}$ Graduanda em Agronomia - UNIOESTE - Universidade Estadual do Oeste do Paraná -Graduanda de Administração - Unip - Universidade Paulista.

${ }^{7}$ Mestrando em Agronomia (Produção Vegetal) pela Universidade Estadual do Oeste do Paraná (UNIOESTE). Engenheiro Agrônomo formado pela UNIOESTE (20142018), atua como pesquisador associado ao Grupo de Estudos em Solos e Meio Ambiente (GESOMA - UNIOESTE). 
cotidianas. O texto reflete também sobre possibilidades e desafios da escola para promover ações pedagógicas que considerem as relações interpessoais no processo de (re)construção do conhecimento. Acena para um trabalho pedagógico crítico investigativo, que de maneira articulada, busque estabelecer vínculos entre práticas cotidianas e a matemática escolar.

Palavras-Chave: Etnomatemática, saber social, conhecimentos matemático, atividades cotidianas, prática pedagógica.

\section{INTRODUÇÃO}

No dia-a-dia do fazer pedagógico, educadores continuam refletindo sobre metodologias de ensino e formas de aprendizagem. Um dos grandes desafios da escola continua sendo contribuir para a formação de cidadãos críticos, conscientes e atuantes na sociedade. Uma tarefa complexa que exige da escola e dos profissionais da educação um movimento que ultrapasse currículo, conteúdo e programa de ensino.

O mundo em que vivemos, embora não nos apercebamos disto, sempre dependeu fundamentalmente da matemática. Ela sempre esteve e está presente em praticamente tudo que nos rodeia. Sua aplicabilidade é relevante até em outras Ciências, como afirma D’Ambrósio (1996, p. 31). "a tendência de todas as ciências é cada vez mais de se matematizarem em função do desenvolvimento de modelos matemáticos que desenvolvem fenômenos naturais de maneiras adequadas."

Como vemos, a matemática está impregnada em todo o entorno social do ser humano e se evidencia a cada nova aprendizagem. Todas as profissões da atualidade se apropriam do conhecimento matemático para criar, manter e sustentar regras, fórmulas e condutas. O pedreiro, a costureira, o cozinheiro, o engenheiro, técnicos de todas as profissões e profissionais de todos os setores da atividade humana dominam algum conhecimento matemático, mas nem sempre aprenderam os cálculos para resolver seus problemas nos bancos escolares. 
Para Rosa Neto (2002), existe uma significativa relação entre a matemática e a cultura, ambas como resultado de nossa adaptação em função de nossas necessidades de sobrevivência através dos tempos, representando ambas, um legado empírico, sistemático e científico.

Trabalhar a etnomatemática no espaço escolar, segundo D’Ambrósio (2008), é contribuir para que as novas gerações conheçam e reconheçam uma matemática muito mais cultural, ligada ao cotidiano de diversos grupos étnicos. Para D’Ambrósio e Rosa (2016), trata-se de uma postura didática que busca uma melhoria no processo de ensino-aprendizagem da disciplina com a incorporação no currículo matemático do conhecimento advindo da vida do aluno e de valores humanos, como, por exemplo, a cooperação, a solidariedade e a ética. São conhecimentos que promovem a valorização e o respeito às maneiras diferentes que a humanidade utiliza diariamente para explicar, entender, compreender e lidar com as situações-problema enfrentadas no cotidiano.

Com essa consciência em relação a importância e o papel da matemática no desenvolvimento dos cidadãos e da sociedade, o presente artigo, além de refletir, busca difundir a etnomatemática, acreditando que ela como proposta pedagógica pode em muito contribuir para amenizar as dificuldades de aprendizagem e falta de interesse de muitos alunos pelo estudo da disciplina.

No nosso entendimento, um trabalho educativo centrado nesta perspectiva, faz o aluno se sentir mais seguro da própria capacidade de construir conhecimentos matemáticos, na busca de soluções para os problemas que ele encontra dentro do seu cotidiano. Para D’Ambrósio (1996), no entanto, é preciso que o professor adote em sala de aula uma nova postura, busque um novo paradigma que substitua o já desgastado ensino-aprendizagem baseado numa relação obsoleta de causa-efeito.

Pompeu e Monteiro (2001, p.14), alertam, ponderando que,

Mudança de paradigma, no entanto, é um processo complexo; é necessário querer mudar e acreditar que isso é possível. Mais do que 
constatar que precisamos mudar, é necessário ter a convicção de que sempre há um novo jeito de ensinar, que sempre é possível mudar.

Os autores enfatizam ainda que trabalhar pedagogicamente nesta perspectiva, exige que o professor compreenda e tenha clareza da abrangência de seu papel, bem como, da importância do conteúdo matemático com que trabalha com os alunos. Em tese, é preciso que seja compreendido o estudante de forma integral, buscando identificar suas necessidades de desenvolvimento no nível intelectual, físico, emocional, social, cultural. Assim sendo, ponderam que,

Os professores atuais têm pela frente um grande desafio: educados num processo fragmentado, terão de superar os limites que essa formação Ihes impõe e extrapolar as fronteiras de conteúdos vistos de forma parcial e a-histórica (POMPEU e MONTEIRO, 2001, p.15).

A tarefa de ensinar e aprender, nesta abordagem, é de fato diferente da tradicionalmente conhecida. Parte-se do que acreditamos ser consensual, ou seja, que todas as culturas e povos têm desenvolvido formas próprias de explicar e modificar a própria realidade. Estes saberes e fazeres presentes em todo processo de desenvolvimento humano, próprios de cada cultura, estão no processo naturalmente, são dinâmicos, em fase de evolução e crescimento constante, contribuindo, portanto, na elaboração do saber sistematizado.

D’Ambrósio (1993), enfatiza de que os povos têm uma cultura [etno], lidam e explicam sua própria cultura [matema], no entanto, cada qual do seu jeito e de sua forma [tica]. Desta constatação resultou a denominação etnomatemática, que por sua vez, leva em conta as explicações próprias das comunidades, gotejando-as com as formas universais de conhecimento. É fato que toda criança antes de chegar na escola sabe lidar perfeitamente com a sua realidade, a qual se encontra em permanente evolução.

Segundo o autor, a etnomatemática parte do princípio e da ideia de incorporar os modelos ligados à tradição e a cultura das crianças, reconhecendo-os como válidos por cumprirem com suas finalidades. Deste modo, a etnomatemática mexe com a 
curiosidade da criançada, volta-se em primeiro lugar, para o ambiente onde ela vive, cumprindo sobremaneira uma tarefa que a escola vem esquecendo: A de libertar e de desenvolver a criatividade dos alunos por meio de projetos investigativos.

Esta perspectiva pedagógica é a chamada etnomatemática, tendência ${ }^{[8]}$ do ensino da matemática que considera em sua prática pedagógica os aspectos sociais e culturais da humanidade. Caracteriza-se como uma tendência de ensino que traz para a discussão e procura refletir sobre as diversas formas de matematizar presentes em nossa realidade sócio cultural.

Propõe uma educação crítica, cuja fundamentação se apoia nos estudos e escritos de Ubiratan D'Ambrósio[ ${ }^{[9]}$, que apontam para uma proposta metodológica de educação matemática que valoriza as vivências dos alunos. Uma visão com feições que perpassam os processos: antropológico, social e político, trazendo à discussão a cultura local de cada grupo social, como atividade humana determinada sócio culturalmente pelo contexto onde se realiza.

É neste aspecto que a etnomatemática, nas últimas décadas, vem se consagrando nacional e internacionalmente como uma proposta didático-pedagógica de ensino da disciplina Matemática. De acordo com D’Ambrósio (2001) "Etnomatemática é a matemática praticada por grupos culturais, tais como comunidades urbanas e rurais, grupos de trabalhadores, classes profissionais, crianças de uma certa faixa etária, sociedades indígenas, e tantos outros grupos que se identificam por objetivos e tradições comuns aos grupos" (p.9).

Trata-se, de acordo com o autor, de uma tendência do ensino onde o conhecimento se manifesta de maneira holística, isto é, possibilita que os diferentes grupos culturais possam conhecer, entender e explicar o seu mundo, utilizando-se da matemática, desenvolvendo habilidades de manejar e interferir, através dela, na sua realidade. Acena para a possibilidade da construção de um currículo escolar que incorpore a vida sociocultural dos alunos nas práticas pedagógicas, como uma das formas de inclusão social. 
Nas palavras de D'Ambrósio (1993) a "Etnomatemática é um programa que visa explicar os processos de geração, organização e transmissão de conhecimentos em diversos sistemas culturais e as forças interativas que agem no e entre os três processos" (p.7).

Nesta tendência de ensino o currículo é dinâmico, contextualizado, reconhece a pluralidade cultural e social dos alunos, possibilita que o educando se torne sujeito ativo, participativo no processo de transformação do seu ambiente local, regional e global.

Em relação ao programa etnomatemática, D’Ambrósio (2001, p. 17) pondera ainda que,

O grande motivador do programa de pesquisa que denomino Etnomatemática é procurar entender o saber/fazer matemático ao longo da história da humanidade, contextualizado em diferentes grupos de interesse, comunidades, povos e nações.

Pompeu e Monteiro (2001), em relação a adoção de uma prática pedagógica que leva o saber/fazer para a sala de aula, argumenta que ele

vem imbuído de certezas que não são "dadas" pela ciência, mas sim por valores, tradições e respeito pelos que ensinam. Assim, tem uma "certeza emocional" confirmada pela experiência, diferente da "certeza científica" que, em geral, é passível de demonstração racional e matemática, apesar de, quando ensinada, também instituir valores emocionais, presentes na pessoa do professor (p.134 - 135).

$\mathrm{Na}$ ação pedagógica a relação a ser estabelecida entre os processos de ensinar e aprender é dialógica, pois é o contexto nestas interações que favorece possibilidades de aprendizagem. Nesta dinâmica, trazer a Etnomatemática e o saber/fazer para a sala de aula, significa recuperar as experiências e os saberes presentes nas atividades cotidianas de diferentes classes trabalhadoras, num esforço de superar o cientificismo do conhecimento acadêmico. 
No entanto, Pompeu e Monteiro (2001), em relação ao trabalhar na sala de aula o conhecimento formal e informal, ponderam que,

[...] é necessário que um grupo saiba e reconheça os limites de seu conhecimento para ir além e buscar o novo com consciência, sabendo e discutindo a importância e validade desse novo. Somente dessa forma ele saberá escolher quando e qual conhecimento usar (p.53-54).

Nas escolas de modo geral se ensina e se aprende apenas a matemática dita como oficial, enquanto que nas atividades cotidianas [comercias, agrícolas, de prestação de serviços, entre outras], se aplicam e se utilizam conhecimentos matemáticos não reconhecidos oficialmente, porém, construídos socialmente, validados e valorizados pela sociedade.

Em suma, por vezes transparece que os cidadãos convivem com a existência de duas matemáticas: A escolar [oficial], vivida dentro das escolas, teórica, abstrata e seletiva e a da vida real que atende as necessidades emergentes dos cidadãos. Percebe-se que esta "outra matemática", raramente aceita pela escola, mostra-se prática, dinâmica e afinada com todos os setores da sociedade, sendo amplamente utilizada nas atividades rotineiras dos cidadãos.

Segundo D’Ambrósio (2001) a Etnomatemática, além de não negar a matemática formal, procura trazer para a discussão cada forma de matematizar, analisando argumentativa e reflexivamente cada contexto onde a matemática está inserida. Compreende e discute as diversas formas de matematizar, desde que sejam atendidos os propósitos de cada contexto, de cada grupo de iguais em suas situações específicas.

Portanto, trabalhar a matemática numa abordagem etno [10], como propõe D’Ambrósio (1993), requer que o educador aprenda a lidar também com os diferentes saberes culturalmente construídos e que circulam entre os alunos. Propõe que a escola repense sua prática, entre em sintonia com as aspirações e necessidades cotidianas das pessoas, resgatando a função social do saber matemático. 
Nessa dinâmica, o educador deve estar aberto às mudanças na forma de agir e trabalhar. Precisa ouvir as experiências que os alunos trazem de casa, da sua comunidade, das relações estabelecidas entre eles, procurando a partir deste processo dialógico-interativo trabalhar o conteúdo matemático. $\mathrm{E}$, além de incorporar em sua prática novas metodologias, analisar e avaliar constantemente sua prática, aprimorando ações pedagógicas já vivenciadas anteriormente. Necessita, enfim, construir o saber matemático a partir das experiências pessoais dos envolvidos no processo educativo.

Desta forma, segundo o Professor Ubiratan D’Ambrósio, a prática da etnomatemática em sala de aula, sugere seguir um caminho muito mais abrangente de socializar e compartilhar saberes distintos.

Ao praticar etnomatemática, o educador atingirá os grandes objetivos da educação matemática, com distintos olhares para distintos ambientes culturais e sistemas de produção. Justifica-se inserir o aluno no processo de produção de seu grupo comunitário e social e evidencia a diversidade cultural e histórica em diferentes contextos (D’AMBRÓSIO, 2008, p, 8).

\section{JUSTIFICATIVA}

Nas escolas, em percentual considerável, percebe-se que o processo ensinoaprendizagem de matemática continua sobremaneira imutável, ou seja, o professor continua a trazer as informações prontas, 0 aluno as recebe passivamente, transparecendo, nestes casos, um acentuado conformismo e determinismo histórico. $\mathrm{Na}$ prática, vê-se ainda uma metodologia desarticulada entre o que se aprende na escola e o que a sociedade realmente exige dos seus cidadãos.

Segundo Santos (2016):

A falta de contextualização no ensino da matemática pode acarretar o desestímulo pela disciplina, ressuscitando os métodos tradicionais que conceituam a matemática como uma ciência que trouxesse todas as 
coisas prontas, como se fosse um conhecimento pronto e acabado. (p. $5)$.

Um ensino que conduz o aprendente a uma aprendizagem mecânica. Além disso ainda existem os que acreditam que o conhecimento matemático é possível apenas para privilegiados, não acessível a todos, o que segundo Ubiratan D’Ambrósio é comparável ao sistema de "casta" aplicada a alguns países.

[...] alguns educadores matemáticos veem a Matemática como uma forma privilegiada de conhecimento, acessível apenas a alguns especialmente dotados, e cujo ensino deve ser estruturado levando em conta que apenas certas mentes, de alguma maneira "especial", podem assimilar e apreciar a Matemática em sua plenitude [...]. (D’AMBRÓSIO, 1996 p.9).

$\mathrm{Na}$ tentativa de minimizar essa situação e trazer motivação e alegria para a sala de aula, buscamos através dessa pesquisa bibliográfica, tanto uma matemática mais contextualizada para os alunos, quanto um caminho metodológico que proporcione melhores resultados. Uma alternativa de ensino que permita mais significação para os conteúdos de matemática estudados. Algo motivador, atrativo e que realmente sirva ao educando de maneira a lhe possibilitar resolver situações-problema de forma contextualizada, inferir e tomar decisões diante de sua realidade, entendendo que, inclusive a matemática formal é viva, está presente no nosso seu dia a dia.

Uma matemática ensinada na escola que se mostre presente na realidade de vida dos alunos, que busque interação entre escola e comunidade, na possibilidade de ser ferramenta de transformação do meio social. Um conhecimento cuja construção e entendimento não seja possível apenas para matemáticos, cientistas, mestres ou doutores, mas também para grupos sociais que desenvolvem ou utilizam em suas atividades laborais habilidades de medir, calcular, desenhar, criar ou jogar, conforme seus interesses e necessidades. 
Que possibilite no e pelo processo ensino-aprendizagem que os alunos se tornem sujeitos singularizados e reflexivos, emancipados, confiantes e interativos na comunidade por meio dos conhecimentos adquiridos. Giardinetto (1999), em seus escritos pondera que o sujeito somente se tornará um cidadão participante de sua sociedade à medida que "apropriar-se de instrumentos culturais" (p.73).

Sabemos e concordamos que a matemática é uma ciência presente tanto no cotidiano dos cidadãos como nos centros de pesquisa. Portanto, considerada esta abrangência não podemos limitar o ensino desta disciplina a uma simples memorização de regras, técnicas e ao conhecimento formal de definições, pois “... ensinar não é transferir conhecimento, mas criar possibilidades para sua própria produção ou sua construção." (FREIRE, 1996, p. 52).

Ensinar matemática na perspectiva da etnomatemática torna-se impossível sem resgatar os saberes e valores que os alunos trazem de casa. Para que este ato se concretize é indispensável ao professor escutar seus alunos, assim como é, indispensável ao aluno que fale ao seu professor e a seus colegas.

Segundo o educador Paulo Freire,

"A construção de relações dialógicas sob os fundamentos da ética universal dos seres humanos, enquanto prática específica humana implica a conscientização dos seres humanos, para que possam de fato inserir-se no processo histórico como sujeitos fazedores de sua própria história". (FREIRE, 1996, p10.)

O educador matemático Paulus Gerdes, em suas várias publicações adota sempre um discurso que resgata as tradições matemáticas dos grupos culturais, que perante a colonização foram sendo segundo ele "escondidas" e impostas por convenções eurocêntricas na sociedade, bem como no espaço escolar.

Assim, nesta perspectiva, (GERDES, 2010, p.142) relata que 
A Etnomatemática é a área de investigação que estuda as multifacetadas relações e interconexões entre ideias matemáticas e outros elementos e constituintes culturais, como a língua, a arte, 0 artesanato, a construção e a educação. É a área de investigação que estuda a influência de fatores culturais sobre o ensino e a aprendizagem da matemática.

Segundo o autor (2010, p.142-143) "a Etnomatemática mostra que ideias matemáticas existem em todas as culturas humanas, nas experiências de todos os povos, de todos os grupos sociais e culturais, tanto de homens como de mulheres". Dentro desta perspectiva cultural, é evidenciado ainda que

[...] todos os povos, de todos os tempos, podem contribuir para esta matemática universal. Todos os povos têm o direito de poder aprender e usufruir o saber acumulado e de poder contribuir para o seu enriquecimento. Reside aqui uma dimensão ética e moral da reflexão Etnomatemática. (GERDES, 2010, p.144)

Vários autores já relataram e pela nossa experiência profissional também já percebemos que as diferentes formas de matematizar estão tão presentes na vida cotidiana dos cidadãos, que muitas pessoas as utilizam nos seus afazeres diários, mesmo nunca tendo frequentado uma escola. Esses conhecimentos, por vezes adquiridos empiricamente, são de um valor extraordinário e de uma riqueza tão significativa que muitos nem sempre tem a sensibilidade para percebê-los. Compartilhamos com Pompeu e Monteiro (2001) ao postularem que,

"O homem se relaciona com o mundo à sua volta, entendido este como mundo-vida, isto é, o mundo em que as pessoas estão dentro, o qual nos educa por meio de influências que chegam a nós por intermédio das nossas relações com ele" (p.21).

Contudo, não se pretende, nesta perspectiva pedagógica propor uma nova matemática, porém, refletir sobre a possibilidade de identificar, nos diferentes grupos 
culturais, seus modos de matematizar, valorizando e considerando suas formas de calcular, de conhecer, explicitar e compreender o mundo que os rodeia, enriquecendo nesta dinâmica, a matemática escolar. Conforme relata D’Ambrósio (2001), trata-se de uma matemática que "... é parte do cotidiano", do saber fazer (p.25). Na verdade, uma proposta pedagógica que trabalha de forma integrada os saberes formais e informais.

Acreditamos que a partir do momento em que se pensa a etnomatemática como alternativa pedagógica que considera a matemática em diferentes ambientes sociais, culturais e históricos, incorpora-se no ensino novas metodologias. Torna-se a matemática escolar um instrumento para explicar e entender o desenvolvimento e a produção dos conhecimentos gerados nesses distintos contextos, motivando os alunos.

Compreender os conhecimentos que são desenvolvidos no interior de uma determinada comunidade é entender a Etnomatemática nesse ambiente, ou seja, é voltar o olhar para as diversas formas de manifestação do conhecimento, não apenas do conhecimento matemático, mas o conhecimento de vida, de organização, de construção e estruturação desses saberes e fazeres que são natos dessas pessoas.

Porém, muitos educadores de matemática, talvez devido a sua formação universitária centrada na linha tecnicista, se mostram com dificuldades em romper com o velho paradigma e adotar uma metodologia de ensino que interliga a matemática escolar com a matemática da vida. Este fato torna-se um obstáculo para que a sala de aula se transforme num espaço para a discussão e análise crítica dos saberes sócio culturalmente construídos. Para Pompeu e Monteiro (2001, p.19), é preciso procurar caminhos para superar os conflitos existentes, pois "vivemos um momento em que a fragmentação do saber limita o entendimento da realidade".

Precisamos estar convictos de que, o que os estudantes fazem e aprendem na escola, pode estar mais alinhado com os fazeres e necessidades dos diversos setores da atividade humana fora dos muros escolares. Basta o educador incorporar e trazer para a sala de aula esses saberes socialmente construídos. Compartilhamos nesta 
pesquisa com os escritos de D'Ambrosio e Rosa, ao considerarem a etnomatemática como um programa de pesquisa em história e filosofia da matemática, com implicações pedagógicas,

Então, esse programa de pesquisa representa uma metodologia de investigação que busca analisar as práticas matemáticas locais, pois visa valorizar, difundir e respeitar o conhecimento matemático (ideias, noções, procedimento, processos e práticas) que se originam em diversos contextos culturais no decorrer da história (D'AMBRÓSIO e ROSA, 2016, p. 17).

Um trabalho pedagógico centrado nesta perspectiva, valoriza o ser humano e seu conhecimento informal constituído na e pela cultura onde vive, pode ser o início de uma mudança no ensino desta disciplina. Segundo D’Ambrósio (2001), um ensino que "revela práticas apreendidas fora do ambiente escolar [pode] contribuir para uma visão crítica da realidade" (p.23).

A escola como instituição que representa a continuação da família em seu contexto mais amplo, deve compreender que todo o processo ensino-aprendizagem que parte das experiências prévias dos cidadãos, das formas de matematizar vivenciadas pelos alunos fora do âmbito da escola, enriquece o ato educativo. Nas palavras de Giardinetto (1999) "a própria vida cotidiana necessita de interferências do nãocotidiano" (p.7).

Neste sentido, deixar-se-ia de trabalhar a matemática oficial como a única matemática que merece atenção. Passar-se-ia a considerar e trazer para a discussão as vivências e os saberes dos alunos anteriores à fase escolar. A escola ao mesclar dialogicamente todos esses saberes transforma a sala de aula num laboratório permanente de aprendizagens.

Nesta tendência, um dos papéis do educador é estimular o desejo natural dos alunos em investigar as diferentes matemáticas utilizadas nos diversos grupos culturais. Ao compreenderem os processos de matematizar de cada cultura, comparam esses 
saberes com o saber formal, sistematizado e validado pela escola, tendo a oportunidade de organizar seu próprio pensamento, compreendendo através desta reflexão a importância cultural e social de cada saber matemático que circula no mundo da vida. Nas palavras de D'Ambrósio (2001), poder-se-ia compreender melhor que "O comportamento de cada indivíduo, associado ao seu conhecimento, é modificado pela presença do outro" (p.32).

Segundo D’Ambrósio (1993), ensinar matemática nesta concepção, significa respeitar o que o aluno já sabe, consiste em reconhecer os saberes historicamente construídos nas culturas, estabelecendo momentos dialógicos de questionamentos críticos que renovam e ampliam os conhecimentos prévios de todos os participantes do processo aprendizagem.

Para D’Ambrósio (2001) respeita-se e se valoriza cada uma das matemáticas existentes, e "... é a comunicação que permite definir estratégias para ação comum" (p.58). A escola, pela reflexão dialética ${ }^{[11]}$, explicita os modos de produção de significados matemáticos produzidos fora de seu contexto específico. Nesta abordagem é como se a matemática escolar se juntasse com as formas de matematizar do mundo circundante, ao invés de substituí-lo. Enquanto a matemática escolar ignora ou não discute essa diversidade de conhecimentos, produzidos na cultura de cada povo, a Etnomatemática valoriza e traz para o debate essas diferenças, reconhecendo seus modelos matemáticos e os conhecimentos a eles vinculados.

Segundo D'Ambrósio (2001), enquanto a matemática tradicional e seu ensino procuram universalizar os conceitos, tornando-os cada vez mais abstratos e generalizantes, a Etnomatemática busca reorganizá-los, tornando-os mais específicos e aplicáveis ao contexto da realidade vivida. Ela propõe, em síntese, um jeito mais coerente de caminhar. Procura trazer a matemática dos livros [da escola] para a vida e a da vida para a escola, reconhecendo que ambas têm uma história e uma importância para a compreensão da realidade em todas as suas dimensões. 
A ideia básica dessa tendência do ensino da matemática, segundo D'Ambrósio (2001), consiste em se considerar as experiências dos alunos, dos familiares, dos grupos de iguais, das diferentes culturas e todas as formas de matematizar próprias de cada povo. São conhecimentos produzidos pela necessidade prática de resolução de problemas específicos de feirantes, pequenos agricultores, pedreiros, carpinteiros, grupos indígenas, colonos assentados etc. São conhecimentos diferentes produzidos por grupos diferentes para elucidar situações-problema.

Para Pompeu e Monteiro (2001), uma prática pedagógica que ao mesmo tempo em que se opõe à fragmentação do conhecimento, caracteriza-se por situar o saber histórico culturalmente e oportunizar os homens ao resgate da sua capacidade crítica dialógica reflexiva. Compreende, de acordo com os autores, o ser humano na sua totalidade e o saber em toda a sua complexidade.

Nas palavras de Pompeu e Monteiro (2001), um ensino que coloca "o homem e não o capital como valor central das relações sociais” (p.26). Segundo D’Ambrósio (2001), um trabalho centrado nesta perspectiva requer dos educadores uma boa dose de humanismo, pois "o aluno é mais importante que programas e conteúdo" (p.86).

A matemática trabalhada numa abordagem etno traz para a sala de aula experiências que exigem comunicabilidade e diálogo argumentativo. Essa postura didática, por sua vez, leva os envolvidos com o processo educativo a um crescimento pessoal e coletivo, possibilitado pela ação reflexiva permanente de ambos e, de ambas as práticas.

Juntos, professor e alunos ensinam e aprendem simultaneamente, conhecem o mundo em que vivem criticamente e constroem relações de respeito mútuo, de justiça, constituindo um clima real de disciplina, por relações dialógicas, tornando a sala de aula um desafio interessante e desafiador a todos os envolvidos. "Quem ensina aprende ao ensinar e quem aprende ensina ao aprender" (FREIRE, 1996, p.38).

Segundo Giardinetto (1999), "o professor pode e deve utilizar o conhecimento cotidiano como ponto de apoio para o processo de ensino-aprendizagem" (p.68), 
trazendo o aluno para o campo da argumentação, desenvolvendo o hábito da leitura crítica, da pesquisa, do questionamento, da criatividade, imprescindíveis para uma formação cidadã.

Ao lançar este olhar sobre sua prática, ficam valorizados os conhecimentos prévios dos alunos e se formam outros, sempre a partir do conhecido. O importante é o estabelecimento de vínculos do conhecimento da comunidade com o conhecimento da escola e do conhecimento da escola com o conhecimento da comunidade. Através deste estabelecimento e destas relações é possível atribuir significado para ambos os saberes. Para D'Ambrósio (2001), neste contexto o conhecimento apresenta um caráter dinâmico, sempre aberto a novos enfoques.

Para Freire (1996) o papel do professor está atrelado à concepção de que ensinar não é transferir conhecimento, mas criar condições para sua construção. Significa reconhecer que juntos, alunos e professores aprendem na sala de aula, já que todos trazem muitos conhecimentos das experiências escolares e não escolares que vivenciaram durante a existência.

Acreditamos que a etnomatemática pode auxiliar cada educador nesta possibilidade pedagógica de substituição das ações rotineiras do "dar aulas prontas" por uma postura que (re)oriente a aprendizagem do aluno na construção de seu próprio conhecimento, fruto da interação entre sujeitos, neste processo dialógico. Até porque a própria sociedade do conhecimento na qual vivemos, exige hoje, uma postura holística na formação dos seus cidadãos, que sejam capazes de interagir com dinamismo em todos os contextos, construam novos significados para a matemática, explorando de diferentes formas situações-problema das diversas atividades humanas.

\section{OBJETIVO}

Contribuir a partir da reflexão para que o educador de matemática adote uma postura crítica investigativa em relação ao ensino de matemática, na perspectiva de iniciar sua 
atividade docente através do estabelecimento de vínculos entre a matemática cotidiana e a matemática escolar.

\section{METODOLOGIA}

As inspirações teóricas deste artigo são decorrentes de leituras e reflexões sobre educação matemática, etnomatemática e a perspectiva intercultural do ensino. Os escritos procuram refletir sobre a abordagem etnomatemática na perspectiva de que um ensino pautado nos conhecimentos prévios dos alunos, valorizando sua cultura e seus modos de matematizar, será fator agregador de conhecimento, dando um caráter mais humano para a disciplina.

\section{CONTRIBUIÇÕES ESPERADAS}

Que seja percebida, segundo D’Ambrósio (2001), a importância da Etnomatemática na formação do aluno, visto que o seu viés cultural e antropológico aponta para o caminho que leva ao respeito às diferenças, compreensão e inclusão, tão necessários à nossa realidade social.

Que ensinar matemática em sala de aula, a partir desta perspectiva pedagógica, permita um diálogo efetivo entre os saberes matemáticos produzidos em diferentes contextos e que os professores reflitam mais sobre a diversidade cultural da disciplina e sua importância para o ensino sistematizado.

Que a partir desta reflexão a prática pedagógica em sala de aula possa ser reorientada para o desenvolvimento da plena cidadania dos alunos. Que, segundo Pinheiro e Rosa (2016), os:

[...] professores de matemática mergulhem na dinâmica cultural dos alunos e utilizem estratégias de ensino e aprendizagem que valorizem a dimensão cultural existente na sala de aula, para que se desenvolva uma educação matemática inclusiva que possa efetivamente contribuir para a transformação social (p. 79). 
Que este esforço possa contribuir com novos elementos para o ensino da disciplina de matemática, permitindo em sala de aula estudarmos cada vez mais matemática e realidade, como formas de conhecer e interpretar cada contexto, num processo no qual o professor estará constantemente (re)produzindo, (re)construindo, (re)significando saberes e conhecimentos.

Esperamos também que os leitores percebam a possibilidade de inserir no ensino de matemática um olhar diferenciado sobre a realidade e sobre a própria matemática e que este olhar corrobore com a aprendizagem matemática do educando de modo a levá-lo a participar de discussões sobre matemática dentro e fora da sala de aula.

Queremos que a sala de aula, a partir da metodologia docente, comece a incorporar/analisar no fazer pedagógico, situações-problema cuja resolução considera tanto a matemática formal quanto a matemática informal. Que a disciplina seja vista como uma atividade humana, motivando ainda mais o interesse dos alunos.

Ressaltamos que não se trata de substituir uma matemática pela outra, mas de respeitar os diferentes modos de matematizar em diferentes contextos, dentro dos propósitos a que estes se propõem. Assim, acreditamos que este enfoque educativo poderá nos remeter a uma educação contextualizada, enriquecida, motivando os participantes por fazerem parte do processo.

Nas palavras de Carneiro um,

[...] ensino da matemática nesta concepção permitirá ao aluno vincular os conceitos trabalhando em classe a sua experiência cotidiana, de acordo com o seu ambiente natural, social e cultural. Não se trata de rejeitar a matemática acadêmica, mas sim incorporar a ela valores que são vivenciados nas experiências em grupo, considerando os vínculos histórico-culturais (CARNEIRO, 2012, p.3).

Enfim, pretende-se contribuir na constituição do professor pesquisador de sua prática, despertando-o a aprender de maneira continuada a ser professor, segundo as atuais necessidades educacionais, transformando a sala aula num ambiente de 
aprendizagem democrático de troca de saberes, resgatando conhecimentos históricosocialmente construídos pela humanidade.

\section{REFERÊNCIAS BIBLIOGRÁFICAS}

CARNEIRO, K. T. A. Cultura Surda na aprendizagem matemática da sala de recurso do Instituto Felipe Smaldone: uma abordagem etnomatemática. Anais do 4ํㅡㄹ Congresso Brasileiro de Etnomatemática. Belém, PA: ICEm4, 2012.

D’AMBRÓSIO, Ubiratan. O programa Etnomatemático: Uma síntese. Acta Scientía, v.10, n.1, Jan/jun.2008.

Etnomatemática - elo entre as tradições e a modernidade. Coleção Tendências em Educação Matemática, 1. Belo Horizonte: Autêntica, 2001, 112p.

Da realidade a ação: Reflexões sobre a educação e matemática. Campinas: Unicamp, 1996.

Etnomatemática: Arte ou técnica de explicar e conhecer. Editora Ática, Série Fundamentos, 2. edição, São Paulo, 1993.

D'AMBROSIO, U.; ROSA, M. Um diálogo com Ubiratan D'Ambrosio: uma conversa brasileira sobre etnomatemática. In BANDEIRA, F. A.; GONÇALVES, P. G. F. (Orgs.). Etnomatemáticas pelo Brasil: aspectos teóricos, ticas de matema e práticas escolares. Curitiba, PR: Editora CRV. 2016. pp. 13-37.

FREIRE, Paulo. Pedagogia da autonomia: Saberes necessário a prática educativa. São Paulo: Paz e Terra, 1996.

GERDES, Paulus. Geometria dos Trançados Bora na Amazônia Peruana, Livraria da Física, São Paulo, 2010, 190 p. São Paulo: Editora Livraria da Física, 2011, 190p.

GIARDINETTO, José Roberto Boettger. Matemática escolar e matemática da vida cotidiana. Coleção polêmicas do nosso tempo, autores associados, Campinas - São Paulo, 1999, 128p. 
MONTEIRO, A.; Pombeu, G. Jr. A matemática e os temas transversais. Editora Moderna, São Paulo, 2001, 160p.

PINHEIRO, R. C.; ROSA, M. Uma perspectiva etnomatemática para o processo de ensino e aprendizagem de alunos Surdos. RPEM, v. 5, n. 9, p. 56-83, 2016.

ROSA NETO, R. Didática da matemática, São Paulo: Ática, 2002.

SANTOS, Lijecson Souza dos. Contextualização Matemática Em Situação De Ensino E Aprendizagem No Eja. Disponível em: https://editorarealize.com.br/revistas/cintedi/trabalhos/TRABALHO_EV060_MD1_SA 18_ID 492_23102016194610.pdf. 2016.

8. Neste trabalho investigativo, utilizada para designar encaminhamento metodológico que pode ser desenvolvido na perspectiva da investigação das concepções, tradições, e práticas matemáticas de um grupo social, através do qual o grupo interpreta e codifica seu conhecimento.

9. Ubiratan D’Ambrósio, professor, educador matemático e pesquisador da Universidade Estadual Paulista (UNESP). Campus de Rio Claro. Instituto de Geociências e Ciências Exatas (IGCE). É Professor Emérito da Universidade Estadual de Campinas/UNICAMP. Tem estudos publicados em: História e Filosofia da Matemática, História e Filosofia das Ciências, Etnomatemática, Etnociência, Educação Matemática e Estudos Transdisciplinares.

10. A abordagem etno se refere a várias perspectivas em circulação a respeito dessa área, a qual não se encontra, até o momento, teoricamente cristalizada. Os educadores e pesquisadores envolvidos com esta questão resolveram dar um tempo para que as explorações avancem e contribuam, assim, para uma possível elaboração teórica da Etnomatemática. É possível que esta elaboração inclua, de modo abrangente, as várias perspectivas em circulação.

11. Dialética nesta reflexão, expressa a arte de buscar pelo diálogo, por meio da argumentação e contra-argumentação a ampliação de ideias e conceitos envolvidos 
na discussão. $\mathrm{Na}$ análise de fatos e situações-problema que permitem o desenvolvimento do pensamento, professor e aluno têm igual participação dialógica, estando um sempre à escuta do outro, (re)construindo juntos suas aprendizagens.

Enviado: Junho, 2019.

Aprovado: Julho, 2019. 